\title{
Transmission of cultural capital and status attainment - an analysis of development between 15 and 45 years of age
}

\author{
Werner Georg University of Konstanz, Germany \\ werner.georg@uni-konstanz.de
}

(Received February 2015

Revised September 2015)

http://dx.doi.org/10.14301/llcs.v7i2.341

\begin{abstract}
Starting with Bourdieu's habitus and capital theory, this paper focuses on the question of whether the cultural resources of families and students have an impact on the status attainment process between the ages of 15 and 45. The analysis is based on the LifE survey, which follows up a youth study conducted by Fend et al. between 1979 and 1983. It can be shown by means of a structural equation model that there is a substantial transmission of cultural capital between parents and their children and that students' cultural resources have an effect on their educational attainment (reproduction effect). Besides this social inheritance, the amount of cultural capital acquired by age 35 also depends on educational attainment. The effect of cultural capital over the life course is limited to the period up to the completion of vocational/professional education.
\end{abstract}

\section{Keywords}

Cultural capital, social inequality, life course, status attainment

\section{Introduction}

Previous empirical assessments of Bourdieu's reproduction theory have resulted in a substantial number of publications (in summary: Jaeger, 2011; Lareau \& Weininger, 2003). Even with Bourdieu himself, both the theory's logical status and its operationalisation are relatively vague. Thus, it can hardly be surprising that research findings are in part heterogeneous, and it is difficult to gain a comprehensive overview. Many studies do not use primary data, but instead draw on a variety of indicators to identify cultural capital, above all on the level of measurement theory. Also problematic are many study designs intended to capture the effects of cultural capital in various life-course segments.

Thus, for example, researchers ask children to recall their parents' cultural capital (Sullivan, 2001). Data collection may be limited to the cultural resources of one parent or the other (De Graaf, 1986) or of students (DiMaggio, 1982).

Furthermore, it is unclear how cultural capital affects status development for people from different classes in different life segments. Bourdieu assumes habitus to remain constant over the life course (hysteresis). This means that cultural capital would have to be significant over an entire life course. In contrast, however, newer biographical research approaches (Kohli, 1988) assume deinstitutionalisation and individualisation of lifecourse-specific patterns.

In another research field, lack of clarity prevails around reproduction theory, which developed during the 1960s in the framework of industrialsocietal structures. There was widespread agreement with regard to "persistent inequality" in the 1990s (Shavit \& Blossfeld, 1993). However, newer studies using larger cumulative data sets increasingly conclude in international comparisons 
that upward mobility clearly did occur in twentiethcentury educational systems (Breen Luijks, Müller \& Pollack, 2010). Furthermore, studies show that schools do not exclusively maintain inequality, but can also contribute to social leveling (for Germany: Meulemann \& Wiese, 1984; for America: Entwistle \& Alexander, 1992). Against this background, we can question the relevance of reproduction theory for contemporary post-industrial societies, especially since the theory is rather hermetically formulated.

In this context, we can propose a few research desiderata. We use a longitudinal data set (LifE Study) that includes information on both parents and children and follows a target cohort over a period of 33 years. On this basis we examine the following questions:

- Through what process is cultural capital transmitted from parents to children?

- Does cultural capital influence children's academic success?

- Up until what point in the life course between 15 and 45 years of age does a target cohort's cultural capital exert influence upon its status development?

- How stable is cultural capital over a life course?

- Do schools independently contribute to developing cultural capital?

\section{Theory}

Alongside rational choice theories, Bourdieu's reproduction theory (Bourdieu \& Passeron, 1971; Bourdieu, 1982; Bourdieu, 1983) has become a dominant paradigm for explaining social inequality in educational systems. The core assumption of this theory is that cultural capital, besides transferring economic capital, plays an increasingly significant role in status acquisition. Bourdieu distinguishes three forms of cultural capital: incorporated, institutionalised and objectified cultural capital.

Embodied cultural capital is internalised within the framework of the family of origin's lifestyle and becomes a 'natural' part of habitus. Family cultural practice is acquired in an extended process as a virtual template, and this template's activation has effects on other people as an integral component of personality. In various passages, Bourdieu emphasises that it is precisely this apparent naturalness of incorporated cultural capital and habitus that constitutes its efficacy in socially reproducing ruling class segments.

Institutionalised cultural capital, in contrast, is transmitted and acquired in a methodical and didactic way in educational institutions within a framework of canonised knowledge resources. These institutions dispose of definition power regarding legitimate knowledge and award credentials attesting to general competence, making accessible specific positions and careers. Moreover, not only is knowledge transmitted in educational systems, but a specific habitus is also expected and rewarded, corresponding to that of groups with power of definition. Besides individual competencies and abilities, in Bourdieu's view, successful completion of a study program presupposes a habitual fit between the milieu of origin and the 'culture' of a respective educational institution or field of study. Objectified cultural capital, after all, refers to the possession of cultural artifacts.

According to Bourdieu, embodied cultural capital is unequally distributed in social space and is monopolised by upper classes (literally: 'ruling classes') as a status marker, enabling members to secure competitive advantages over lower classes in educational systems. A necessary core assumption of reproduction theory is that unequally distributed, embodied cultural capital is also passed on to successive generations in the form of familial socialisation processes.

Social inequality in educational systems arises in this context because schools (and universities) implicitly presuppose certain amounts of embodied cultural capital that make it possible to accumulate institutionalised cultural capital in school frameworks. Successful educational habitus is thereby constituted through both familiarity with the dominant 'legitimate' culture and behaviour and non-cognitive abilities such as discipline, high levels of commitment, and belief in one's own selfefficacy. What remains relatively hazy from this viewpoint, however, is how lower-class children are disadvantaged in everyday school interactions. Are cognitively relevant curricular deficiencies responsible (according to Boudon (1974), thus primary effects of origin), or different linguistic codes (Bernstein, 1972), or the self-confident demeanor and presentation characteristic of upperclass habitus, or do teachers arbitrarily reward students who recognise habitual signals of their 
own class of origin? This distinction is significant insofar as only differences in competence would be subject to meritocratic legitimisation.

Sullivan (2002) is correct in holding that, with regard to theoretical testability, central elements of Bourdieu's reproduction theory are still astonishingly vague. This is true not only for underlying core processes, such as acquiring embodied cultural capital or the above-described concomitant school interaction and devaluation of lower-class students, but also for the question of how cultural capital can then be measured and operationalised. Thus, it is surprising how much paradigmatic significance reproduction theory has acquired and how many international studies build on this theory.

\section{Previous research}

Various empirical studies have given rise to criticism of Bourdieu's capital and reproduction theory. Bourdieu's own empirical findings are limited to bivariate correlations between, on one side, family of origin status and cultural practices, and, on another, class-specific school success. To find support for reproduction theory, it would first be necessary to develop a theoretically grounded measurement theory of cultural capital. After that, one would have to demonstrate intergenerational transmission of cultural capital, and ultimately a substantial effect of incorporated cultural capital on measurements of academic success and later professional status. Previous research has examined only part of this causal chain, and for some data, measurement quality is only to a limited extent satisfactory.

DiMaggio (1982), as well as DiMaggio and Mohr (1985), have examined Bourdieu's assumptions together with Max Weber's status culture theory. In their analyses, they used data from the TALENT Project. Their sample consisted of eleventh-grade students, surveyed in different types of schools. They factor analytically measured cultural capital using indicators such as interest in attending classical music concerts, participating in theatre groups and artistic activities, reading 'serious' literature and having a cultivated self-image. This factor served as an independent variable to explain students' grades in various different subjects. The father's educational attainments (diplomas) and language skills were control variables in a regression model. The strongest effect was demonstrable in English, whereby only language skills and cultural capital exerted influence, but not the father's professional status. In addition, two competing hypotheses were tested - namely 'reproduction hypothesis' and 'mobility hypothesis'. The first hypothesis deals with monopolisation of cultural capital as an indicator of upper-class status culture; the second hypothesis asserts that lower classes can use cultural capital as a means of upward mobility. Confirmation of the reproduction hypothesis could only be found for female respondents, while for male students across all groups, effects varied only to a limited extent and tended rather to confirm the mobility hypothesis. DiMaggio suspects that, for boys, cultural capital has relatively limited influence on upper-class reproduction, because 1960s sons from this group belonged to non-conformist youth sub-cultures that rejected high-cultural lifestyles.

De Graaf (1986) analysed the influence exerted by cultural capital on educational achievements of families' oldest and second-oldest children. For cultural capital, he used two scales: 'parents' cultural consumption' measured by theatre visits, museum visits and visiting historical buildings, and 'reading climate': reading 'serious' literature and visiting libraries. As latent control variables in a structural equation model, he used parents' socioeconomic status (educational attainments of father and mother, as well as the father's professional status), family income and number of siblings. He subdivided the sample into two cohorts (children aged 25-40 and 41-65). His study showed that family socioeconomic status exerted only limited influence on reading climate, but reading climate exerted strong effects on educational attainment. This pattern was reversed for cultural consumption, which depended strongly on family sociocultural background, but had no effect on children's educational success. This finding, in contrast to Bourdieu's assumptions, supports the supposition that high culture does not determine educational outcomes, but rather serves as an indicator for high status culture in Weber's sense. In contrast, reading climate, which serves as an indicator for cognitive and linguistic skills, strongly influences educational outcomes; however, this influence is only half as strong in the younger cohort.

Similar to the above study, De Graaf, De Graaf \& Kraaykamp (2000) propose differentiating between 
cultural consumption and reading behaviour. They reason that, in countries with modernised school systems like the Netherlands, compared to France, high-cultural content is not as strongly anchored in curricula. In contrast, they assume that developed parental reading culture enables children to acquire language and cognitive skills that make it easier to succeed in modern democratised school systems. In a second step, the authors test DiMaggio's reproduction and mobility thesis using a sample of respondents to the 1992/93 Dutch family survey. On this basis, they calculated three sequential regression models, whereby the first model analysed the influence of cohorts, gender, incomplete families, parental educational attainments and fathers' professional status on children's school attainments. Results showed that parents' education level exerted a significantly stronger influence on children's educational status than the father's profession. In a second step, a combined measure of cultural capital was introduced containing five items related to cultural consumption and reading behaviour. In this model, the predictive power of parental educational attainments and that of the father's professional status decreased substantially. In a final step, they divided the common scale for cultural capital into two subscales for cultural consumption and reading behaviour. In this model variant, only parental reading behaviour significantly influenced children's educational status. To test the reproduction and mobility hypotheses, in the last two model variants constructed the interaction effects between parental educational accomplishments and various measures of cultural capital. This combined scale for cultural capital had a strong negative effect, which suggests that children from families with low educational achievement use cultural capital as a means of upward mobility. Separating the two measures again showed a non-significant effect of cultural consumption, while reading behaviour had almost the same predictive power as the combined scale. One can summarise these results as follows:

In contrast to Bourdieu's results for France in the 1960 s and 1970s, consumption of high culture is no longer significant for explaining school success in modernised educational systems like those in the Netherlands. However, cultural capital operationalised as reading behaviour in the sense of verbal and cognitive abilities proved a strong predictor of school success. In this variant, cultural capital serves as an instrument of upward mobility and not as a means of social closure for higher status groups.

Sullivan (2001) surveyed students in four English classes aged 16 with regard to their socioeconomic background and cultural activities in the areas of reading, television consumption, taste in music and participation in high-cultural events, and finally tested their language skills and cultural knowledge. In addition, students were asked about their parents' cultural capital, which was measured in number of books per household, parental reading habits, music and media consumption, participation in high-cultural activities, and topics discussed at home. In a statistical analysis, the influence of cultural capital on children's school success was modeled in three steps: first, a regression model was calculated in which parents' school education, professional status and the types of school attended by children were used as predictors for children's cultural activities. In this connection, membership of the higher service class (Goldthorp class schema) and university degrees turned out to be significant. Parental cultural activities were added in a further model. In this model, the previous model's significant effects disappeared, and only cultural capital exerted a significant influence. These results support intergenerational transmission effects of cultural capital. In two further steps, the effects of the above-named children's cultural practices on language and cultural knowledge tests were examined. Above all, watching thought-provoking television programs and reading intellectually challenging literature were significant predictors, whereas participating in musical activities and formal cultural events had no substantial effects. There were similar findings for the knowledge test, with the exception that the order was reversed. As the last link in a causal chain, the influence of the named variables on a combined index was examined with regard to all of the children's school grades. Aside from scores on the two skill tests, reading behaviour and TV consumption were again the factors with significant effects. In summary, the analysis was successful in modeling cultural capital influences insofar as interconnected causal influence could be shown, starting from the transmission effect up to influences on school performance. Again, it was reading behaviour and not participation in high- 
cultural activities that influenced abilities and school success.

Baumert, Watermann \& Schümer (2003) analysed the transmission of social inequality using data from the PISA 2000 Study for Eastern and Western Germany in the framework of a family process model that distinguished three levels. Exogenous variables were family socioeconomic status (measured by highest ISEI - International Socio-Economic Index) and educational level (highest school diploma), as well as immigration status and length of residence in Germany. Mediating variables were three latent variables: cultural practice in Bourdieu's sense (investment in cultural artifacts like books or artworks, shared family cultural activities), family-internal communicative practice as described in Coleman's social capital theory (1988), and consumption behaviour (owning luxury goods etc.), alongside two manifest variables: number of siblings and languages spoken at home. The dependent variable was the test score for reading ability. While family cultural practices proved to be strong predictors of reading ability, social capital and consumption behaviour had no substantial effect in this regard. Additionally, the number of siblings and languages used at home had only weak effects. Cultural practice was strongly influenced by the family's socioeconomic background and education levels, while social capital was relatively independent of both factors. Finally, consumption behaviour showed medium dependence. In Eastern Germany, the percentage of explained variance in reading ability was lower, but predictions of test scores showed almost the same pattern as in Western Germany. However, cultural practice was less dependent on families' socioeconomic and educational status, and immigration status had a lower indirect influence on reading ability. The authors conclude from the findings that the concept of cultural capital, which in this model only passes on the effects of social inequality (professional status and education), has significantly greater construct validity than Coleman's concept of social capital.

What observations can we make against the background of previously discussed empirical findings? As a general conclusion, we find that cultural capital can be regarded as a key concept for the transmission of social inequality between generations in various countries. However, in modernised school systems the tendency seems to be that the relevant factor in transmitting social inequality is not participation in high-cultural activities, but rather family reading culture. If the latent variable for cultural capital in the study by Baumert et al. (2003) is deconstructed into measures of attending cultural institutions (museums, theatre, opera) and measures of reading behaviour (number of books in household, possession of classical literature and poetry books), only reading behaviour influences reading ability (author's calculations, publication in preparation). This circumstance makes us ask whether, with this operationalisation of cultural capital, it is not more a matter of transmitting cognitive abilities than of arbitrary familiarity with elements of the dominant high culture. This topic will be dealt with in greater detail below. We still do not know whether upper classes use cultural capital to reproduce their status, or lower and middle classes use it as an instrument of social mobility. DiMaggio's findings support the first assumption only for girls, while De Graaf et al. (2000) found support for the second hypothesis. Most of the studies discussed above feature specific deficiencies in their sampling design or measurements of cultural capital. De Graaf (1986) criticised DiMaggio (1982) for obtaining information only about students' cultural capital but not parents'; as a result, analysis of the transmission process becomes impossible. In contrast, De Graaf's data (1986) included only information on parental cultural activities. Sullivan (2001) reconstructed parental cultural capital using information provided by children, a problematic method with regard to data validity.

\section{Excursus: Measurement theoretical considerations of cultural capital and implications for this study}

As is clear from the above overview of previous research, there is no unified measurement or theoretical concept for cultural capital. This may also be the case because Bourdieu's theoretical formulation $(1982,1983)$ is relatively vague in this regard, which has resulted in different definitions and operationalisation methods being used in previous research (Jaeger, 2011; Lareau \& Weiniger, 2003).

For Bourdieu himself (1982, pp. 800 ff.), cultural capital referred above all to high-cultural practices (reading literature, media consumption, music, 
attending cultural events, aesthetic preferences) and knowledge of cultural fields (composers, directors, musical pieces). As already shown above, however, research has made an initial rough differentiation between high-cultural practices (Aschaffenburg \& Maas, 1997; DiMaggio, 1982; Dumais, 2002; Kalmijn \& Kraykamp, 1996; Katsillis \& Robinson, 1990; Sullivan, 2001; Van de Werfhorst \& Hofstede, 2002) and reading behaviour or reading culture (De Graaf, 1986; De Graaf et al., 2000; Jaeger \& Holm, 2007). Besides this differentiation, education-related resources and materials (Deutsches PISA-Konsortium, 2001; Downey, 1995; Eitle \& Eitle, 2002; Teachman, 1987), as well as extra-curricular or voluntary school activities (Aschaffenburg \& Maas, 1997; Covay \& Caborno, 2010; Kaufmann \& Gabler, 2004) were drawn on to measure cultural capital.

Lareau and Weininger (2003) criticise the dominant definition, narrowly tied to high-cultural practices, of cultural capital and - drawing on different sources of Bourdieu - propose a broader definition related to negotiating processes for legitimating partial status signals between parents and institutional agents of the education system:

"As we noted earlier, in our view the critical aspect of cultural capital is that it allows culture to be used as a resource that provides access to scarce rewards, is subject to monopolisation, and, under certain conditions, may be transmitted from one generation to the next..." (Lareau \& Weininger, 2003, p. 587).

Suppose one starts from this general definition of cultural capital and understands it as a cultural resource that can be monopolised and that creates access to scarce rewards. This definition would then subsume not just arbitrary familiarity with status signals of legitimate high culture, but also linguistic and cognitive competencies mediated within a family's reading culture.

In view of the definitions and measurement concepts used in previous research on cultural capital, we can summarily conclude that in this regard controversies exist over both theory and operationalisation. Of course, this makes it more difficult to compare findings, but we can nonetheless maintain that, despite these differences, most studies agree that cultural capital exerts a moderate to medium influence on measures of academic success (grades or diplomas).
What do these results mean for evaluating the measures used in this study for cultural capital and their usefulness? First, for parental cultural capital beginning in 1980 we must draw on the few available indicators, namely frequency of reading, number of books per household and course attendance. Overall, this operationalisation is thereby very close to the concept of family reading culture used by De Graaf (1986), as well as De Graaf et al. (2000), and is less oriented to families' highcultural practices. In both studies, however, it was also found that effects on children's academic success arose solely from reading culture and not from consuming high culture.

Besides reading, available indicators for students aged 15 included particularly music-related activities, namely learning to play a musical instrument and listening to classical music. In a newer DIW (German Institute for Economic Research - Deutsches Institut für Wirtschaftsforschung) study (Hille \& Schupp, 2013), it was shown that youth between the ages of eight and 17 who practiced playing musical instruments did better by a quarter of a standard deviation on cognitive language tests than students of the same age lacking this practice, and their average grade was one-sixth of a standard deviation better. Furthermore, they were a quarter of a standard deviation more conscientious and more open, and the probability that they would graduate from a gymnasium (secondary school leading to university study) and want to attend a university was 15\% higher than in a comparison group (Hille \& Schupp, 2013, p. 23). In this study, a multiplicity of control variables with regard to parents were used and reverse causality was investigated. So far, it appears that, besides reading books, playing musical instruments is a promising indicator for cultural reproduction in educational systems. Listening to classical music serves in this connection as an indicator for high-cultural orientation of young people.

For follow-ups in 2002 and 2012, a new instrument was developed to capture cultural capital, from which, after factor analysis, three items with the highest loading were used (attending classical concerts, theatre performances and art exhibitions, reading 'serious' literature and listening to classical music).

It could be said that, given the various sorts of definitions and measuring concepts of cultural 
capital presented above, employing only three items for parents and youths per measurement time-point is not very meaningful. However, in almost all the studies presented above, only a few items were used (usually between two and four indicators per dimension), and in cumulative consideration the state of findings is consistent insofar as, usually, moderate or medium effects on academic success could be ascertained. In addition, measurements of parental reading culture and highcultural practices of surveyed persons move within the two 'mainstream' dimensions for measuring cultural capital.

\section{Research Questions and Hypotheses}

To correct the deficiencies mentioned above in the previous research on cultural capital and social reproduction, it would be desirable to compare the different influencing factors (e.g. reading habits and cultural consumption) used in previous surveys for both parents and children in order to analyse specific transmission processes, and then to predict what influence these factors have on social status development over the course of life. However, the available data do not include all the information that would be needed for this, and the following analyses are limited to parts of such models. First, the available measures of these factors are limited to combined indicators for reading behaviour and cultural consumption, and second, we can only predict the impact of these factors on educational and training achievements, along with occupational status at ages 35 and 45 . Against this background, certain research questions and hypotheses can be formulated, derived from Bourdieu's theory and the recent research discussed above.

Classical path models for status acquisition (Blau \& Duncan, 1967) conceptualise the direct transmission of parents' educational attainment to their children's academic careers. These models can be used to analyse openness and social mobility (or social closure) in various societies. Here, however, it remains unclear what processes cause social status transmission from one generation to another. According to Bourdieu's theory, family cultural resources could be the key concept for the inheritance of social status. This would mean that after controlling for direct paths between parents' and children's education levels, a substantial indirect effect should be found that would function through parents' cultural resources and their transmission to children.

Hypothesis 1: In addition to a direct transmission effect of parents' educational attainments to those of their children, there are also indirect effects connected with the transmission of cultural resources from parents to children (transmission effect) and a resulting effect of this on children's own educational attainments (reproduction effect).

Furthermore, Bourdieu supposes that embodied cultural capital's influence is not limited to the results of educational processes, but also influences future professional careers, because mastery of complex cultural codes here leads to competitive advantages.

Hypothesis 2: Cultural resources influence not only levels of educational attainment, but also professional status development over the life course.

According to Bourdieu, habitus is embodied during primary socialisation, and over a life course becomes a dominant personality component.

Hypothesis 3: Cultural capital does not change substantially over a person's life course.

Reproduction theory assumes that incorporated cultural capital is learned exclusively in a family of origin framework (reproduction model). Based on previous studies (e.g., in Germany: Meulemann \& Wiese, 1984; in America: Entwisle \& Alexander, 1992), however, we can postulate that, as middle class institutions, schools do not serve, as Bourdieu thought, solely to disadvantage lower-class children, but can very well exert egalitarian influences on the acquisition of cultural capital (mobility model). Thus, in the Netherlands, Nagel (2010) found in a separate test of these effects on persons between 14 and 24 years of age that the parental home certainly had a significant effect, but both school and home show effects largely independent of each other.

"An increase in cultural participation due to increasing educational level occurs for both children of culturally active family backgrounds and children whose parents have less interest in cultural activities." (Nagel, 2010, p. 553)

On this basis, two competing hypotheses were formulated concerning the reproduction and mobility models: 
Hypothesis 4a: Consistent with reproduction theory, cultural capital is acquired exclusively in family frameworks.

Hypothesis 4b: Cultural capital is, based on the mobility model, acquired not only in families, but also in school frameworks.

\section{Data and Measurements}

The following analyses are based on two followups of a student survey (2002 and 2012) conducted with a 1979-1983 panel designed by Fend et al. (LifE-Survey: Lebensverläufe ins fortgeschrittene Erwachsenenalter; Pathways from late Childhood to Adulthood. Principal Investigators: Fend, Lauterbach, Grob, Georg \& Maag Merki). In 1982, the students were on average 15, in 2002 on average 35, and in 2012 on average 45 years old. The survey covers a cohort from three Frankfurt city districts (Bockenheim, Westend, and Nordweststadt) and Odenwald, a rural district. In these districts, surveys were made of students from all school types who were in sixth grade in 1979. In all, 2,897 students participated at one point in the panel study section, and 1,790 respondents participated at all four measurement times. Due to absence, repeating a class or moving out of their school district, about $14 \%$ of participating students changed per year (i.e., some participants withdrew and were replaced). Within the sample context, hauptschüler and gymnasiasten (students in lower secondary schools and secondary schools leading to university study) are slightly under-represented compared to State Statistical Office data, while a strong bias can be observed regarding students from integrated comprehensive schools (gesamtschule, $30.9 \%$ in sample, and $16.8 \%$ in Hesse). Other differences can be found in a smaller representation of rural and small town residents $(62.2 \%$ vs. $74.1 \%)$ and working class students (28.2\% vs. $44.3 \%$ ) (Fend, 1990).

In 1980 and 1982, students' parents were also interviewed. As part of an address study conducted between 2000 and 2002, it was possible to locate 2,021 of 2,897 students originally questioned at least once. Since 154 addresses were found to be incorrect, the final sample consisted of 1,867 people, of whom 1,527 (81.8\%) participated in the 2002 survey. A significant selection effect of this sample in comparison to the original survey can be shown for nationality (German-background students participated more often), city size (large city residents are under-represented), social class (continuous participation declines with lower social status), and school type (larger panel loss of middle school students). The survey was conducted in spring/summer 2002 as a mail survey, where, in addition to a 10 Euro incentive bonus, reminder letters were sent and follow-up telephone calls were made. These two measures increased questionnaire returns to $15.7 \%$ and $22.2 \%$. The follow-up survey included various 'subjective' and 'objective' indicators from the areas of school and work, family of origin, politics and worldview, leisure, and lifestyle, as well as psychological and physical health.

Between 2010 and 2012, a further address study was made, in which 1,599 target persons were identified as potential participants (net sample). In spring/summer 2012, a mail survey was again conducted, with a total of 1,368 respondents participating; the response rate was $85.55 \%$. Measures intended to increase response rates were identical to those in 2002 (financial incentives, reminder letters, follow-up telephone calls).

Besides the target cohort (G2), questionnaires were sent (G3) to 685 children between 12 and 18 years old; these partially replicated questionnaires from interviewed students. From this cohort, 581 respondents answered, and thus here the response rate was $85.11 \%$. In the following analyses, the only data used were for parental generation (G1) and target cohort (G2). 
Figure 1: Design of the LifE Study

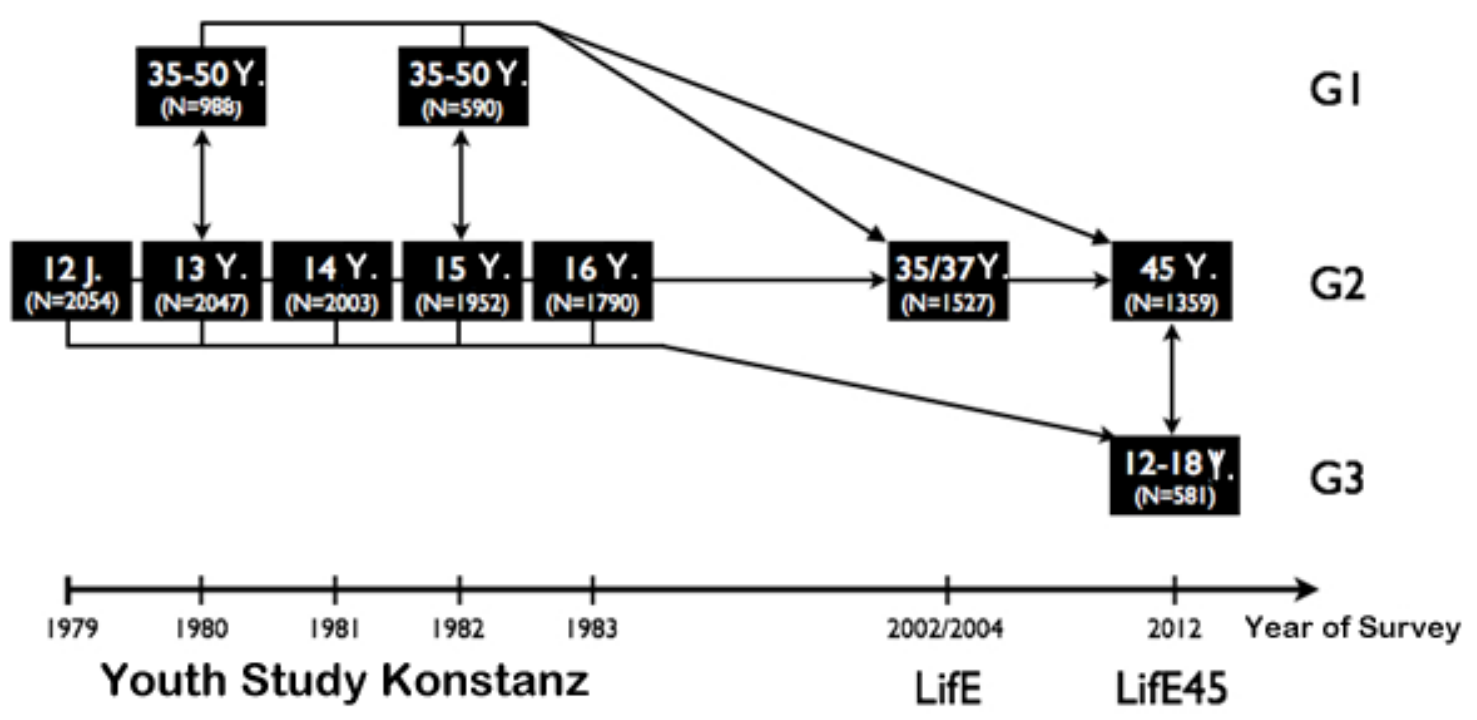

In the structural equation model presented below, the following variables are used (means and standard deviations given in Appendix 1):

\section{Cultural capital of G1 in 1980:}

Frequency of reading in last three months $(1=$ never $-4=$ more than twice monthly)

Course attendance in last three months $(1=$ never $-3=$ more than twice)

Number of books in household ( $1=$ up to $10-4=$ more than 500$)$

\section{Cultural capital of G2 in 1982:}

Frequency of practicing a musical instrument $(1=$ never $-4=$ very often $)$

Frequency of reading books ( $1=$ never -4 very often)

Frequency of listening to classical music ( $1=$ never $-4=$ very often $)$

Cultural capital of $\mathbf{G 2}$ in 2002:

Frequency of reading 'serious' literature ( $1=$ never -5 = very often $)$

Frequency of attending classical concerts, theatre and art exhibitions ( $1=$ never $-5=$ very often $)$

Frequency of listening to classical music or jazz $(1=$ never $-5=$ very often $)$

\section{Cultural capital of $\mathbf{G 2}$ in 2012:}

Frequency of reading 'serious' literature (for range, see above)

Frequency of attending classical concerts, theater and art exhibitions (for range, see above)

Frequency of listening to classical music or jazz (for range see above)

\section{Socio-demographic variables:}

\section{G2 in 2002:}

Highest school diploma ( 1 = primary school $-5=$ higher education entrance qualification/Abitur)

Highest level of education ( $1=$ apprenticeship $-5=$ university degree $)$

Gender ( 1 = female, 2 = male)

Socioeconomic status of profession according to International Socio-Economic Index (ISEI, Ganzeboom et al., 1992, range 16-90)

G2 in 2012:

Highest educational degree of father and mother ( 1 = primary school $-4=$ university entrance qualification certificate (Abitur) (asked retrospectively with respect to G1)

ISEl of current main profession. 


\section{Results}

In order to analyse the reliability of the measures for cultural capital preceding the structural equation model, Cronbach's Alpha was computed for each dimension:

\section{Table 1: Cronbach's Alpha for the Latent Dimensions}

\begin{tabular}{ll}
\hline Dimension & Alpha \\
\hline Cultural Capital Parents 1980 & .59 \\
Cultural Capital Child 1982 & .55 \\
Cultural Capital 2002 (35 years) & .64 \\
Cultural Capital 2012 (45 years) & .63 \\
\hline
\end{tabular}

As Cronbach's Alpha depends on the number of items and the dimensions of the model only consist of three items, these values can be regarded as satisfactory (Nunally, 1967).

To test the four hypotheses described earlier in this paper, a structural equation model was developed that included the following measurement model:

Parents' cultural capital (1980) was calculated from the frequency of reading and course attendance in the past three months. In addition, this dimension was associated with the number of books in the parental household. Cultural capital for children at age 15 (1982) was measured based on the frequency of practicing musical instruments, reading books, and listening to classical music. Twenty years later, cultural capital was measured for participants, now on average 35 years old, based on their frequency of reading 'serious' literature, attending theatre performances, classical concerts and art exhibitions, and listening to classical music or jazz. The same measurement model was used in 2012 for now 45-year-old respondents. An autocorrelation of measurement error was allowed for the same items measured in the ten-year period.

Educational status of the family was determined by the highest educational degree of the father and mother, while the highest level of school education and training completed determined that of their children. To capture how the status acquisition process progressed, the ISEI at ages 35 and 45 was included in the model. In this measurement model, respondents' cultural capital was collected over a period of 30 years, three times over the course of development. Two indicators were identical (reading and listening to classical music), while one indicator was different for reasons of varying agespecific cultural practices (people usually learn to play musical instruments in their childhood and youth, and classical concerts or art exhibitions are chiefly attended by adults).

In order to check hypothesis 1 at a structural level, first, a direct influence of parents' educational status on that of their children was assumed (direct educational inheritance), and a path to parents' cultural capital was introduced. It was further supposed that this cultural capital affects children's cultural capital at age 15 (transmission path). To analyse Bourdieu's predicted reproduction effect, it was further suggested that cultural capital at age 15 affects surveyed students' educational status. In addition to the direct effects of parents' educational level, indirect reproduction effects through cultural resources were thus posited.

Hypothesis 2 is related to long-term effects of cultural capital on professional status development, independently of its effects on achieved educational status. Therefore, aside from the effects of educational attainment on professional status, direct effects of cultural capital at age 35 were allowed for in the ISEI in both 2002 and 2012. Additionally, the effects of cultural capital were allowed for in the ISEI at age 45 in 2012.

Finally, hypothesis 3, based on an assumption of habitus hysteresis, posits that cultural capital will be highly stable over the life course. This assumption is 
tested by allowing for the direct effects of cultural capital between ages 15 and 35, and between 35 and 45.

In competing hypotheses $4 \mathrm{a}$ and $4 \mathrm{~b}$, the reproduction model was contrasted with the mobility model with regard to the acquisition of cultural capital. In order to test the two hypotheses, a path was identified from the educational status of individuals surveyed to their cultural capital at age 35.

The thus-specified structural equation model was calculated with Mplus version 7.11 using a WLSMV estimator (Weighted Least Square Mean and Variance Adjusted) for ordinal data. In contrast to full information maximum likelihood or simple maximum likelihood estimators, the WLSMV estimator is distribution free (non-parametric) and assumes no metrical scale niveau or normal distribution of variables; it is thereby suitable for an ordinal scale niveau. The missing value algorithm of this estimator is based on a 'pairwise present' regression approach, i.e., probit regressions are calculated to predict missing values between available pairs of variables (Muthén \& Muthén, 2012 , p. 8). Accordingly, the respective number of cases varies, and there are in all a maximum of 1,339 cases. In order to compare the sensitivity of this missing value algorithm with a case-wise exclusion (listwise deletion) of missing values, the model was calculated using both procedures. However, no substantial differences were found, so it can be assumed that the results are stable in this regard.

To test the model's goodness-of-fit with the data, different measures are used in Mplus. The likelihood test compares the null hypothesis that the empirical covariance (or correlation) matrix and the matrix estimated based on the model are exactly identical to the alternative hypothesis that the two matrices are significantly different. A problem with the likelihood test is that it is almost always significant if the sample size is large, and therefore the model has to be rejected. Consequently, fit measures independent of sample size are increasingly being used. In this connection, absolute and incremental fit measures can be distinguished. As an absolute fit measure, one can use the Root Mean Square Error of Approximation (RMSEA), which measures approximate data fit. Bentler's (1990) Comparative Fit Measure (CFI) and the Tucker-Lewis Index (TLI) can be regarded as incremental fit measures. In different ways, both measure deviance from a baseline model in which only variances of observed variables are taken into consideration, but they have no relationships in the form of covariances (Muthén, 1998-2004, p. 23). Based on simulation studies, $\mathrm{Hu}$ and Bentler (1999), as well as Yu and Muthén (2002), hold that models with a good fit should have a RMSEA $<.05$ and a CFI or TLI >.95.

De Graaf et al. (2000) and Sullivan (2001) found that reading behaviour had a stronger effect on educational success than knowledge and practice in the field of high-brow culture. In order to test this assumption, two models were estimated, one with the indicators for cultural capital mentioned above and the other one solely with reading practice. However, in contrast to the findings of De Graaf et al. (2000), the effects of reading behaviour on educational attainment turned out to be insignificant. 
Table 2: Direct and Indirect Effects of the Model (standardised)

\begin{tabular}{|c|c|c|}
\hline Effect & Beta & P-Value \\
\hline $\begin{array}{l}\text { Education Parents - Cultural } \\
\text { Capital Parents }\end{array}$ & .75 & $<.001$ \\
\hline $\begin{array}{l}\text { Education Parents - Cultural } \\
\text { Capital Parents }\end{array}$ & .38 & $<.001$ \\
\hline $\begin{array}{l}\text { Cultural Capital Parents - } \\
\text { Cultural Capital Child } 1982\end{array}$ & .45 & $<.001$ \\
\hline $\begin{array}{l}\text { Cultural Capital Child } 1982 \text { - } \\
\text { Educational Status }\end{array}$ & .28 & $<.001$ \\
\hline $\begin{array}{l}\text { Educational Status Child - } \\
\text { Cultural Capital Age } 35\end{array}$ & .26 & $<.001$ \\
\hline $\begin{array}{l}\text { Educational Status Child - ISEI } \\
2002\end{array}$ & .76 & $<.001$ \\
\hline $\begin{array}{l}\text { Educational Status Child - ISEI } \\
2012\end{array}$ & .28 & $<.001$ \\
\hline ISEI 2002 - ISEI 2012 & .57 & $<.001$ \\
\hline $\begin{array}{l}\text { Cultural Capital } 1982 \text { - Cultural } \\
\text { Capital } 2002\end{array}$ & .60 & $<.001$ \\
\hline $\begin{array}{l}\text { Cultural Capital } 2002 \text { - Cultural } \\
\text { Capital } 2012\end{array}$ & .91 & $<.001$ \\
\hline $\begin{array}{l}\text { Cultural Capital } 2002 \text { - ISEI } \\
2002\end{array}$ & & n.s. \\
\hline $\begin{array}{l}\text { Cultural Capital } 2002 \text { - ISEI } \\
2012\end{array}$ & & n.s. \\
\hline $\begin{array}{l}\text { Cultural Capital } 2012 \text { - ISEI } \\
2012\end{array}$ & & n.s. \\
\hline $\begin{array}{l}\text { Cultural Capital Parents } 1980 \text { - } \\
\text { Cultural Capital Child } 1982 \text { - } \\
\text { Educational Status Child } 2002\end{array}$ & .13 & .001 \\
\hline
\end{tabular}


Figure 2: Structural equation model of cultural capital's influence on status development between 15 and 45 years of age

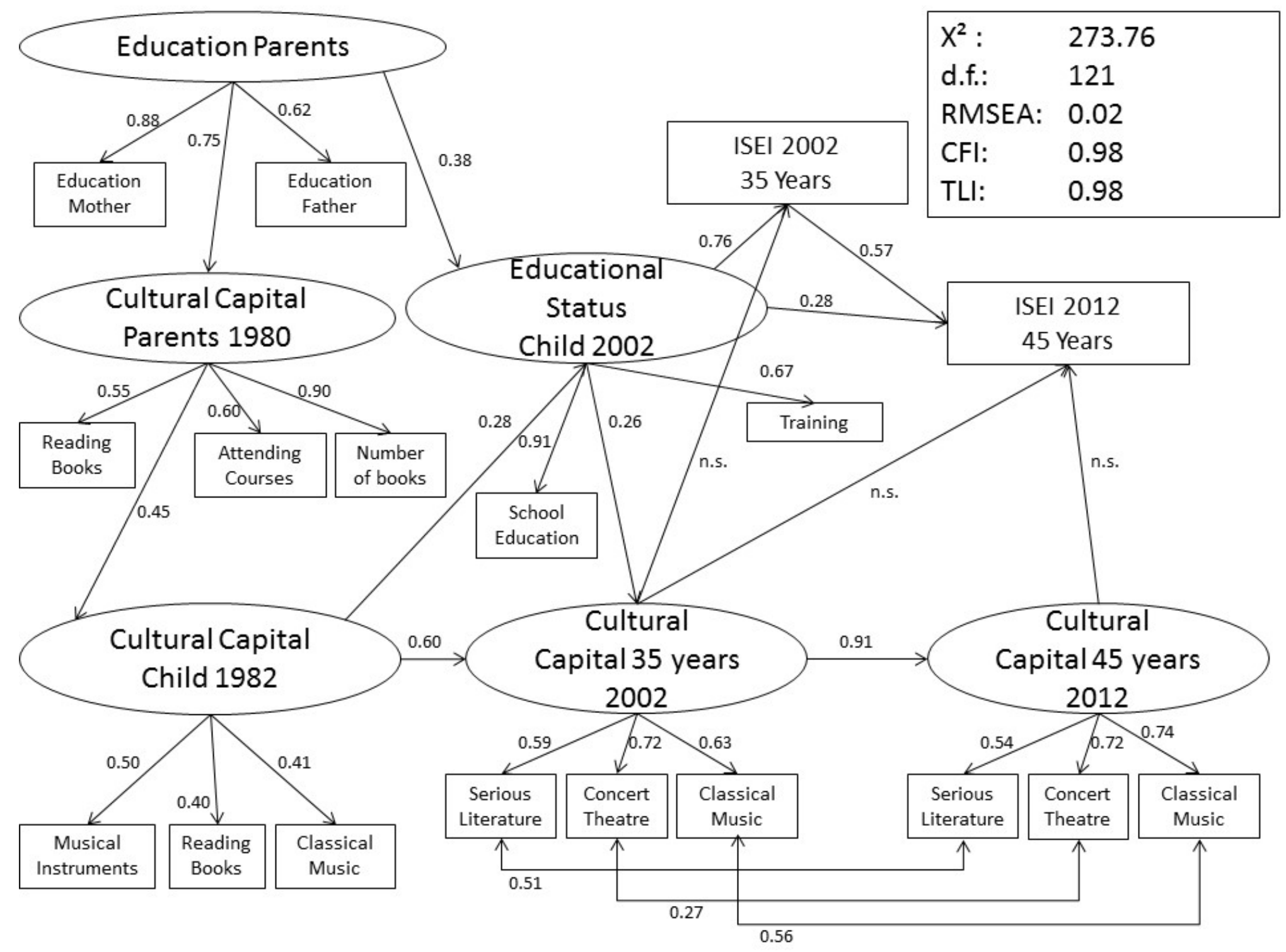


The estimated structural equation model should be rejected based on the likelihood chi-square test ( $p<.001$ ), as was also expected because of sample size. However, the RMSEA (.02) and the CFI and TLI (both .98) point to a very good model fit with the data. In figure 2, all coefficients shown are standardised and significant at least at the $5 \%$ level. In the measurement model framework, the number of books per family household proves by far the most important indicator of parents' cultural capital (.90), whereas reading books and attending courses are about equally important (.55 or .60). In children's cultural capital at age 15 (1982), practicing a musical instrument (.50) is slightly more relevant for the latent variable than reading books and listening to classical music (.40 or .41). At age 35 , attending concerts, theatre and art exhibitions (.72) are slightly weightier than reading 'serious' literature (.59) and listening to classical music (.63), whereas ten years later both attending high-cultural events and listening to classical music (.72 and .74) are substantially more important than reading 'serious' literature (.54).

In the model's structural part, there is a close relationship between parents' educational attainments and their cultural capital (.75). The transmission effect of parents' cultural capital to that of their children (.45) indicates strong effects of learning cognitive schemata during primary socialisation and thereby supports Bourdieu's theory of habitus inheritance. Furthermore, there is a substantial path from children's cultural capital to educational status identified in 2002 (.28). Based on these findings, hypothesis 1 cannot be rejected, according to which a (indirect) reproduction effect was posited via transmission of cultural capital within families parallel to the direct effect of parents' education on that of their children.

The influence of cultural capital on the status attainment process is only significant until professional/occupational training is completed, and occupational status at age 35 is exclusively predicted by the educational status attained (.76). Furthermore, cultural capital had no significant effects either in 2002 or 2012 on occupational status at age 45 . Occupational status at 45 can best be predicted using ISEI at age 35 (.57), but beyond this, it is also still linked with educational attainment (.28). The status development coming to light here thus suggests that after career training is completed, the effects of educational and vocational systems are strongly intertwined alongside labour market-immanent processes of labour mobility. In summary, we can conclude that, overall, a student's cultural capital has effects only until their career training is completed. The assumption made in hypothesis 2 cannot be confirmed here, that cultural capital has an effect on status development throughout the course of a person's life.

The third hypothesis, assuming hysteresis of habitus, posited a high stability of cultural resources over a life course. The present data set provides a rare opportunity to investigate the stability of cultural capital using three measurements over a period of 30 years. Although only two of the three indicators are identical between 15 and 35 years of age, the use of a different item is due to agespecific cultural practices. Stability is remarkably high between 1982 and 2002, with a coefficient of .60 after an interval of 20 years. Even more remarkable is the fact that, with an identical measurement at a ten-year interval, a stability coefficient of .91, i.e., $83 \%$ variance in 2012 , can be predicted with measurements from 2002, and the indirect stability effect from 1982 to 2002 and 2012 amounts to .55. Thus, hypothesis 3 cannot be rejected.

Concerning hypotheses $4 \mathrm{a}$ and $4 \mathrm{~b}$, two possible modes for acquiring cultural capital during the life course are imaginable: namely, quasi-class-based acquisition in the parental home, as reflected here in the high transmission effect of .45, and 'meritocratic' acquisition through educational systems (Nagel, 2010). Thus, by separating these effects between 14 and 24 years of age, Nagel (ibid.) found that parental home effects were indeed more important, but the two modes of acquisition display effects that are largely independent of each other. The path leading from children's educational status to their cultural capital at age 35 confirms this (.26). In the period studied, cultural resources are thus acquired in two different ways, namely, on one hand, by cultural inheritance aided by the parental home and, on another, through mediation in educational institutions. This finding conflicts with Bourdieu's supposition that embodied cultural capital is acquired exclusively within family contexts. 


\section{Discussion}

Empirical study of Bourdieu's posited reproduction of socioeconomic status through cultural capital transmission at home has drawn attention to certain desiderata. Thus, past research has focused either solely on the effects of children's cultural resources on their academic success (DiMaggio, 1982), which makes an analysis of transmission processes impossible, or has analysed only parents' cultural capital (De Graaf, 1986). Sullivan (2001) and Yaish \& Katz-Gerro (2010) chose a third approach and reconstructed parents' cultural capital using information provided by their children. This, however, raises issues of data validity. Moreover, with cross-sectional data collection, the duration of cultural capital influence over a person's life course remains uncertain, and the causal direction of status attainment processes underlying social reproduction cannot be adequately captured. Although some panel studies have been made in this area (Aschaffenburg \& Maas, 1997; Kloostermann, Notten, Tolsma \& Kraykaamp, 2011), and although data on parents' and children's cultural capital were not collected separately in these studies, the time periods analysed were relatively short (e.g., seven years, Kloostermann et al., 2011) and were limited to periods of school attendance. With the data available here, some of the desiderata can be realised:

- Separate collections of the cultural capital of parents and children make it possible to examine the scope of transmission processes.

- Over a period of 30 years, there are in each case three measurements of target cohort cultural capital (at 15, 35 and 45 years of age). In addition, the status attainment process was also surveyed over the same period (educational attainment, training qualification and occupational/professional status at 35 and 45 years), so that over this period processes of creating social inequality in dependence on cultural capital can be successively modeled.

Starting from four hypotheses about the processes of reproduction through cultural resources, their efficacy, and their stability in life course segments, we reached these key conclusions:

- Parents' cultural capital depends strongly (.75) on their educational status, and we can identify a definite process of transmission to their children (.45). Children's cultural capital affects their educational and training attainments in a substantial way (.28). Thus, some social reproduction occurs through family cultural resources.

- The effects of cultural capital over the life course are, contrary to Bourdieu's theory, limited to the period up to completion of vocational/professional training. Then, further development follows through a synchronization of educational and vocational systems (statutory regulation of access to professional positions) as well as labour-market-internal processes in which educational status continues to play a role beyond previously achieved professional status.

- Additionally, contrary to Bourdieu's suppositions, embodied cultural capital is not acquired exclusively in families (class model), but also in educational systems ("meritocratic" model).

- Between 15 and 45 years of age, there is a high stability of cultural capital (.60 between 15 and 35 years, as well as .91 between 35 and 45 years of age). This finding suggests that orientation to high culture is an integral part of habitus that does not change greatly between ages 15 and 45 .

How can we relate these results to Bourdieu's theory of cultural capital, habitus, and social reproduction? First, it has been confirmed, as in the studies presented here, that there are substantial moderate effects of family cultural resources on children's academic success. However, the strength of these effects is far from the only deterministic explanation for success in educational systems, and over the life course is limited to the phase up until completion of training. Furthermore, school cannot be regarded as merely a middle class institution that blocks chances for educationally disadvantaged families and children. Rather, it also has, once children have gained access to higher education (which is increasingly common), a leveling effect (.26) on cultural capital by the age of 35 . Against this background, Bourdieu's theory seems too hermetically formulated with regard to processes of reproduction through cultural capital. While family of origin cultural resources appear important, they are not the sole mechanisms of transmitting (or reducing) social inequality. 


\section{References}

Aschaffenburg, K. \& Maas, I. (1997). Cultural and educational careers: The dynamics of social reproduction. American Sociological Review 62, 573-587. http://dx.doi.org/10.2307/2657427

Baumert, J., Watermann, R. \& Schümer, G. (2003). Disparitäten der Bildungsbeteiligung und des Kompetenzerwerbs. Ein institutionelles und individuelles Mediationsmodell. Zeitschrift für Erziehungswissenschaften 6, 46-72. http://dx.doi.org/10.1007/s11618-003-0004-7

Bentler, P. M. (1990). Comparative fit indexes in structural models. Psychological Bulletin 107, 238-246. http://dx.doi.org/10.1037/0033-2909.107.2.238

Bernstein, B. (1972). Studien zur sprachlichen Sozialisation. Schwann: Düsseldorf.

Blau, P.M. \& Duncan, O. D. (1967). The American occupational structure. New York: Wiley.

Boudon, R. (1974): Education, opportunity and social inequality. New York: Wiley.

Bourdieu, P. \& Passeron, J.C. (1971). Die Illusion der Chancengleichheit. Stuttgart: Klett.

Bourdieu, P. (1982). Die feinen Unterschiede. Kritik der gesellschaftlichen Urteilskraft. Frankfurt a.M.: Suhrkamp.

Bourdieu, P. (1983). Ökonomisches Kapital, kulturelles Kapital und soziales Kapital. In Kreckel, R. (Hrsg.): Soziale Ungleichheiten (Soziale Welt, Sonderband 2). Göttingen: Verlag Otto Schwartz, 183-198.

Breen, R. \& Goldthorpe, J. (1997). Explaining educational differentials: towards a formal rational action theory. Rationality and Society 9, 275-305. http://dx.doi.org/10.1177/104346397009003002

Breen, R., Luijks, R., Müller, W. \& Pollack, R. (2010). Long-term trends in educational inequality in Europe: Class inequalities and gender differences. European Sociological Review 26, 31-48. http://dx.doi.org/10.1093/esr/jcp001

Coleman, J. (1988). Social capital in the creation of human capital. American Journal of Sociology 94, 95-120. http://dx.doi.org/10.1086/228943

Covey, E. \& Carbonaro, W. (2010). After the bell: Participation in extracurricular activities, classroom behavior, and academic achievement. Sociology of Education 83, 20-45. http://dx.doi.org/10.1177/0038040709356565

De Graaf, N.D., De Graaf P.M. \& Kraaykamp, G. (2000). Parental cultural capital and educational attainment in the Netherlands: A refinement of the cultural capital perspective. Sociology of Education 73, 91111. http://dx.doi.org/10.2307/2673239

De Graaf, P.M. (1986): The impact of financial and cultural resources on educational attainment in the Netherlands. Sociology of Education 59, 237-246. http://dx.doi.org/10.2307/2112350

Deutsches PISA-Konsortium (Hrsg.) (2001). PISA 2000. Basiskompetenzen von Schülerinnen und Schülern im internationalen Vergleich. Opladen: Leske und Budrich.

DiMaggio, P. \& Mohr J. (1985). Cultural Capital, educational attainment and marital status. American Journal of Sociology 90, 1231-1257.

DiMaggio, P. (1982). Cultural capital and school success: the impact of status culture participation on the grades of US highschool students. American Sociological Review 47, 189-201. http://dx.doi.org/10.2307/2094962

Downey, D.B. (1995). When bigger is not better: Family size, parental resources and children's educational performance. American Sociological Review 60, 746-761. http://dx.doi.org/10.2307/2096320

Dumais, S.A. (2002). Cultural capital, gender and school success: The role of habitus. Sociology of Education 75, 44-68. http://dx.doi.org/10.2307/3090253

Eitle, P.M. \& Eitle, D.J. (2002). Race, cultural capital and the educational effects of participation in sports. Sociology of Education 75, 123-146. http://dx.doi.org/10.2307/3090288

Entwisle, D.R. \& Alexander, K.L. (1992). Summer setback: Race, school composition and mathematics achievement in the first two years of school. American Sociological Review 57, 72-84. http://dx.doi.org/10.2307/2096145

Fend, H. (1990). Vom Kind zum Jugendlichen. Der Übergang und seine Risiken. Entwicklungspsychologie der Adoleszenz in der Moderne. Band 1. Bern, Stuttgart, Toronto: Huber. 
Ganzeboom, H.B.G., De Graaf, P.M., Treiman, D.J. \& de Leeuw, J. (1992). A standard international socioeconomic index of occupational status. Social Science Research 21, 1-56. http://dx.doi.org/10.1016/0049-089X(92)90017-B

Hille, A. \& Schupp, J. (2013). How learning a musical instrument affects the development of skills. SOEPpapers 591, 1-33. http://dx.doi.org/10.2139/ssrn.2338467

Hu, L.T. \& Bentler, P.M. (1999). Cutoff criteria for fit indices in covariance structure analysis: conventional criteria versus new alternatives. Structural Equation Modeling 6, 1-55. http://dx.doi.org/10.1080/10705519909540118

Jaeger, M.M. \& Holm A. (2007). Does parent's economic, cultural and social capital explain the social class effect on educational attainment in the Scandinavian mobility regime? Social Science Research 36 , 719-744. http://dx.doi.org/10.1016/j.ssresearch.2006.11.003

Jaeger, M.M. (2011). Does cultural capital really affect academic achievement? New evidence from combined sibling and panel data. Sociology of Education 84, 281-298. http://dx.doi.org/10.1177/0038040711417010

Kalmijn, M. \& Kraaykamp G. (1996): Race, cultural capital and schooling: An analysis of trends in the United States. Sociology of Education 69, 22-34. http://dx.doi.org/10.2307/2112721

Katsilis, J. \& Robinson, R. (1990). Cultural capital, student achievement and educational reproduction: The case of Greece. American Sociological Review 55, pp. 270-279. http://dx.doi.org/10.2307/2095632

Kaufmann, J. \& Gabler, J. (2004). Cultural capital and extracurricular activities of girls and boys in the college attainment process. Poetics 32, 145-168. http://dx.doi.org/10.1016/j.poetic.2004.02.001

Kloostermann, R., Notten, N., Tolsma, J. \& Kraaykamp, G. (2011): The effect of parental reading socialization and early school involvement on children's academic performance: A panel study of primary school pupils in the Netherlands. European Sociological Review 27, 291-306. http://dx.doi.org/10.1093/esr/jcq007

Kohli, M. (1988): Normalbiographie und Individuum. Zur institutionellen Dynamik des gegenwärtigen Lebenslaufregimes. In Brose, H.G. \& B. Hildenbrand. (Eds.). Vom Ende des Individuums zur Individualität ohne Ende. Leverkusen: Leske \& Budrich, pp. 33-54. http://dx.doi.org/10.1007/978-3322-97182-1_2

Lareau, L. \& Weininger E.B. (2003). Cultural capital in educational research: A critical assessment. Theory and Society 32, pp. 568-606. Theory and Society 32, pp. 568-606. http://dx.doi.org/10.1023/b:ryso.0000004951.04408.b0

Meulemann, H. \& Wiese, W. (1984). Bildungsexpansion und Bildungschancen. Zeitschrift für Sozialisationsforschung und Erziehungssoziologie 4, pp. 287-306.

Muthén, B.O. (1998-2004): Mplus technical appendices. Los Angeles, CA: Muthén \& Muthén.

Muthén, L.K. \& Muthén, B.O. (1998-2012). Mplus User's Guide. Seventh Edition.

Nagel, I. (2010). Cultural participation between the ages of 14 and 24. Intergenerational transmission or cultural mobility. European Sociological Review 26, 541-556. http://dx.doi.org/10.1093/esr/jcp037

Nunally, J. C. (1967). Psychometric theory. New York: McGraw-Hill.

Shavit, Y. \& Blossfeld H.P. (Eds.) (1993). Persistent inequality: Changing educational attainment in thirteen countries. Boulder, Colo.: Westview Press.

Sullivan, A. (2001). Cultural capital and educational attainment. Sociology 35, 893-912. http://dx.doi.org/10.1177/0038038501035004006

Sullivan, A. (2002). Bourdieu and education: How useful is Bourdieu's theory for researchers? The Netherland's Journal of Social Sciences 38, 144-166.

Teachman, J.D. (1987). Family background, educational resources and educational attainment. American Sociological Review 52, 548-557. http://dx.doi.org/10.2307/2095300

Van de Werfhorst, H.G. \& Hofstede, S. (2007). Cultural capital and relative risk aversion? Two mechanisms for educational inequality compared. British Journal of Sociology 58, 391-415.

http://dx.doi.org/10.1111/j.1468-4446.2007.00157.x

Weber, M. (1976). Wirtschaft und Gesellschaft. Grundriss der verstehenden Soziologie. Tübingen: Mohr. 
Yaish, M. \& Katz-Gerro, T. (2010). Disentangling 'cultural capital': The consequences of cultural and economic resources for taste and participation. European Sociological Review 26, 1-17.

Yu, C.-Y. \& Muthén, B. (2002). Evaluation of model fit indices for latent variable models with categorical and continuous outcomes. Technical Report. Los Angeles, CA: Muthén \& Muthén.

\section{Appendix}

\section{Appendix 1: Mean and Standard Deviation of Variables Employed}

\begin{tabular}{lll}
\hline Variable & Mean & SD \\
\hline Education Father & 1.40 & .62 \\
Education Mother & 1.38 & .62 \\
G1 Frequency of Reading & 2.50 & 1.21 \\
G1 Frequency of Course Work & 1.46 & .72 \\
G1 Number of Books & 2.47 & .78 \\
G2 Musical Instrument & 1.80 & .98 \\
G2 Reading Books & 2.50 & .91 \\
G2 Classical Music & .53 & .72 \\
G2 (2002) Highest School-leaving Qualification & 1.20 & .73 \\
G2 (2002) Highest Training Qualification/Degree & 2.09 & 1.51 \\
G2 (2002) Serious Literature & 1.90 & 1.00 \\
G2 (2002) Concerts, Theater, Art Exhibits & 1.93 & .86 \\
G2 (2002) Classical Music, Jazz & 1.87 & 1.07 \\
G2 (2002) ISEI & 48.57 & 13.88 \\
G2 (2012) 'Serious' Literature & 2.00 & 1.20 \\
G2 (2012) Concerts, Theatre, Art Exhibits & 1.94 & .90 \\
G2 (2012) Classical Music, Jazz & 2.00 & 1.04 \\
G2 (2012) ISEI & 48.84 \\
\hline
\end{tabular}

